\title{
INTERACTION OF XYLAZINE WITH GALLAMINE OR TOLAZOLINE ON THE NEUROMUSCULAR JUNCTION OF ANAESTHETISED DOGS
}

\author{
Ibrahim M. El-Ashmawy, Ahmed I. Bayomi* \\ and Abd El-Hasseib Fayed** \\ Departments of "Pfarmacology, Surgery * atd Physiology *", \\ Faculty of 'Veterinary Medicine, Alexandria University, 'Egypt
}

\begin{abstract}
Xylazine was tested on the neuromuscular transmission in anaesthetised dogs. In addition, its interactions with gallamine and tolazoline on the upper lip muscles of anaesthetised dogs have been studied. Xylazine inhibited neuromuscular transmission. Furthermore, xylazine potentiated the neuromuscular blocking action of gallamine. Pretreatment with tolazoline, prevented the depressant effect of xylazine on the neuromuscular transmission. At the same time, xylazine significantly prolonged the duration of anaesthesia caused by thiopental sodium in dogs. It could be concluded that xylazine inhibited neuromuscular transmission centrally via its action of the $\propto-2$ adrenoceptors and its effect was potentiated with gallamine and prevented with tolazoline.
\end{abstract}

\section{INTRODUCTION}

Xylazine is a well known sedative in veterinary practice. When xylazine is injected alone or concurrently with other anaesthetics, it produces sedation, analgesia and muscle relaxation via its action on the central nervous system ${ }^{(1-4)}$.

Meanwhile, xylazine induces central muscle relaxation leading to general muscle relaxation which supplements the state of sleep and freedom of pain. This effect is based on inhibition of the interneural transmission impluses ${ }^{(\mathbf{5})}$.

Obviously, minor surgery and ceasareans are accomplished after administration of xylazine and local anaesthetics ${ }^{(6)}$. However, yohimbine and atipamezole effectively reverses the sedative effects of xylazine ${ }^{(7,8)}$.

There is no available data about the effect of xylazine on the neuromuscular transmission in dogs and its interaction with drugs commonly used during anaesthesia as muscle relaxants.
The present work was undertaken to study the duration of action of xylazine in dogs. The effect of pretreatment with the competitive neuromuscular blocker (gallamine) or the antihypertensive drug (tolazoline) on the neuromuscular blockade induced by xylazine was also investigated.

\section{EXPERIMENTAL}

\section{Materials :}

Xylazine (Bayer, Leverkusen, Germany), gallamine triethiodide (Flaxedil, Alex. Chemical Co., Egypt) tolazoline (Sigma, Chemical Co. U.S.A), thiopental sodium (Bio chemie), neostigmine bromide (Sigma) and heparine (Nile Co., Egypt) were used in this study and dissolved in saline solution.

The upper lip muscles preparation:

The preparation was performed according to the method described before ${ }^{(9)}$, fifteen dogs of both sex weighing from $10-15 \mathrm{~kg}$. (b.wt.) were anaesthetised using thiopental sodium 
10 mgeg to wis in the saphenoss vent af the lest The dogs were divided into thece eroughs of 5 . The lad group was unected with wylazne $1 \mathrm{mg} / \mathrm{kg}$ (b.w. 1,2 , the and group was injected with 2 mekg b w and the 3 ad group injected with 3 mg/kg (b.wi).

The rachea was cannulated and vendillation was controlled when requared using AMBU apparatus consusting of a self inflating valve and rebreathing valve. The dog was placed in a lateral recumbency position. The area of the check was surgically prepared. A transwerse incision was made in the skin of the facial crest (about $1.2 \mathrm{~cm}$ ) under the lateral canthus of the eye to expose the dorsal buccal branch of the facial nerve. The nerve was freed from its surrounding connective tissue. A strong thread was passed through the upper lip of the operated side by means of a surgical needle and tied upon it. The thread was passed across two pullies to be connected to the lever. The nerve was electrically stimulated every 10 seconds interval by supramaximal single shocks of 1 msec. duration with a B. Braun stimulator Tracings were recorded on smoked paper on a B. Braun kymograph using side writing spring lever.

After tracing the normal contractions of the upper lip facial nerve preparation, xylazine or gallamine alone was injected into the cannulated saphenous vein and the premedication with gallamine or tolazoline prior to xylazine were recorded. The recovery index (the time required for recovery between $25 \%$ and $75 \%$ of the control value) was studied as described earlier ${ }^{(10)}$

Statistical analysis of the obtained data were performed by standard method(11).

\section{RESULTS}

Xylazine $1 \mathrm{mg}, 2 \mathrm{mg}$ and $3 \mathrm{mg}$ $\mathrm{mg} / \mathrm{kg}$. (b.wt.) reduced the indirectly elicited muscle twitches by $12.00 \pm 0.60$, $19.00 \pm 1.30$ and $33.62 \pm 1.75$ percent, respecuvely compared with the controt (Fig, 1)

The interaction of xylazine $(3 \mathrm{mgfag}$ b.wt.) with gallamine $(0.7 \mathrm{mg} / \mathrm{kg} \mathrm{b}$. wi) and tolazoline (1 mg/kg b.w.) wat tested. It was found that the injection of xylarine and gallamine resuled in potentiation and prolongation of the imhibitory effect of gallamine on the neuromuscular transmission (Fig. $2 \& 3$ ). The maximum inhibition of neuromuscular transmission with xylazine $(3$ $\mathrm{mg} / \mathrm{kg})$, gallamine $(0.7 \mathrm{mg} / \mathrm{kg})$ and xylazine plus gallamine was $33.62 \pm 1.75$. $37.90 \pm 3.52$ and $68.69 \pm 4.28$ percent respectively.

The recovery index was $10.0 \pm 0.07$, $6.16 \pm 0.07$ and $21.12 \pm 0.57$ minutes. respectively.

On the other hand, the pretreatment with tolazoline significantly blocks the depressant effect of xylazine previously recorded on the neuromuscular transmission (Fig.4). At the same time. xylazine prolonged the duration of anaesthesia produced by thiopental sodium from $17.25 \pm 11$ to $66.25 \pm 5.54$ min.

\section{DISCUSSION}

The present work was performed to demonstrate the effect of xylazine on the neuromuscular transmission in dogs, and its interaction with the competitive neuromuscular gallamine. At the same time, the influence of xylazine on the duration of anaesthesia produced by thiopental sodium in dogs was also investigated.

Xylazine given i.v. induced a dose-dependent transient partial neuromuscular blockade. It was observed that dogs were more resistant to xylazine than other animals as the dose of 0.05 to $0.1 \mathrm{mg} / \mathrm{kg}$ (i.v) was very effective in cattle, while the effective dose in horse was 0.5 to $1.0 \mathrm{mg} / \mathrm{kg}$ (b.wt., i.v) and produced its effect in 1 to 2 minutes (6). However,in this study, the administration of $1 \mathrm{mg} / \mathrm{kg}$ (b.wt., i.v) produced a very slight neuromuscular blockade in dogs. 


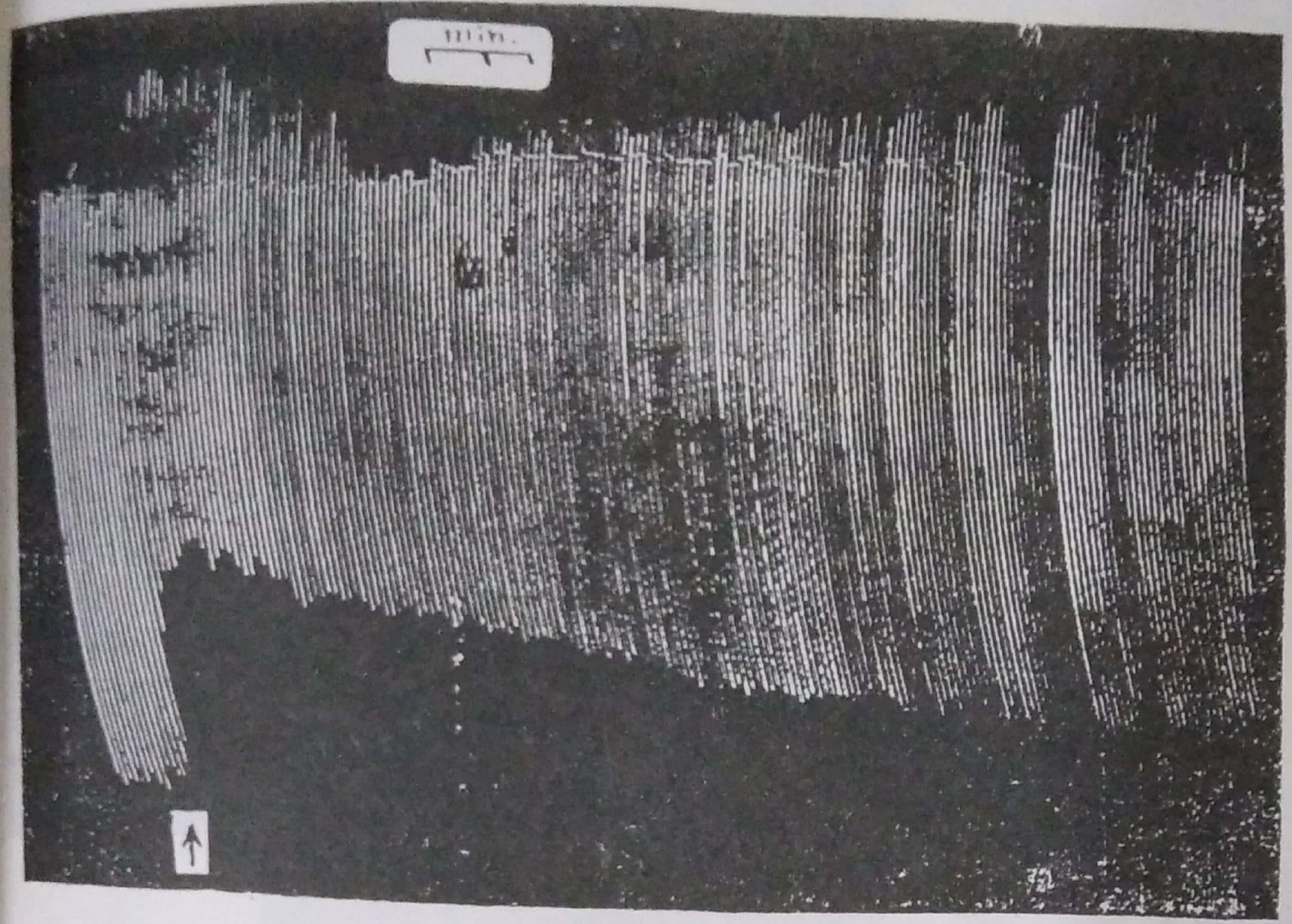

\section{Xylazine \\ $(3 \mathrm{mg} / \mathrm{kg}$ )}

Fig. (1): The effect of xylazine $(3 \mathrm{mg} / \mathrm{kg}$. i.v) on the indirectly elicited muscle twitches of the upper lip muscles of anaesthetised dogs. The nerve was stimulated by a square pulse wave of 6 volts and of $1 \mathrm{msec}$. duration repeated every 10 seconds interval. Time interval: 1 minute.

Note: Partial neuromuscular blockade induced by the drug. 


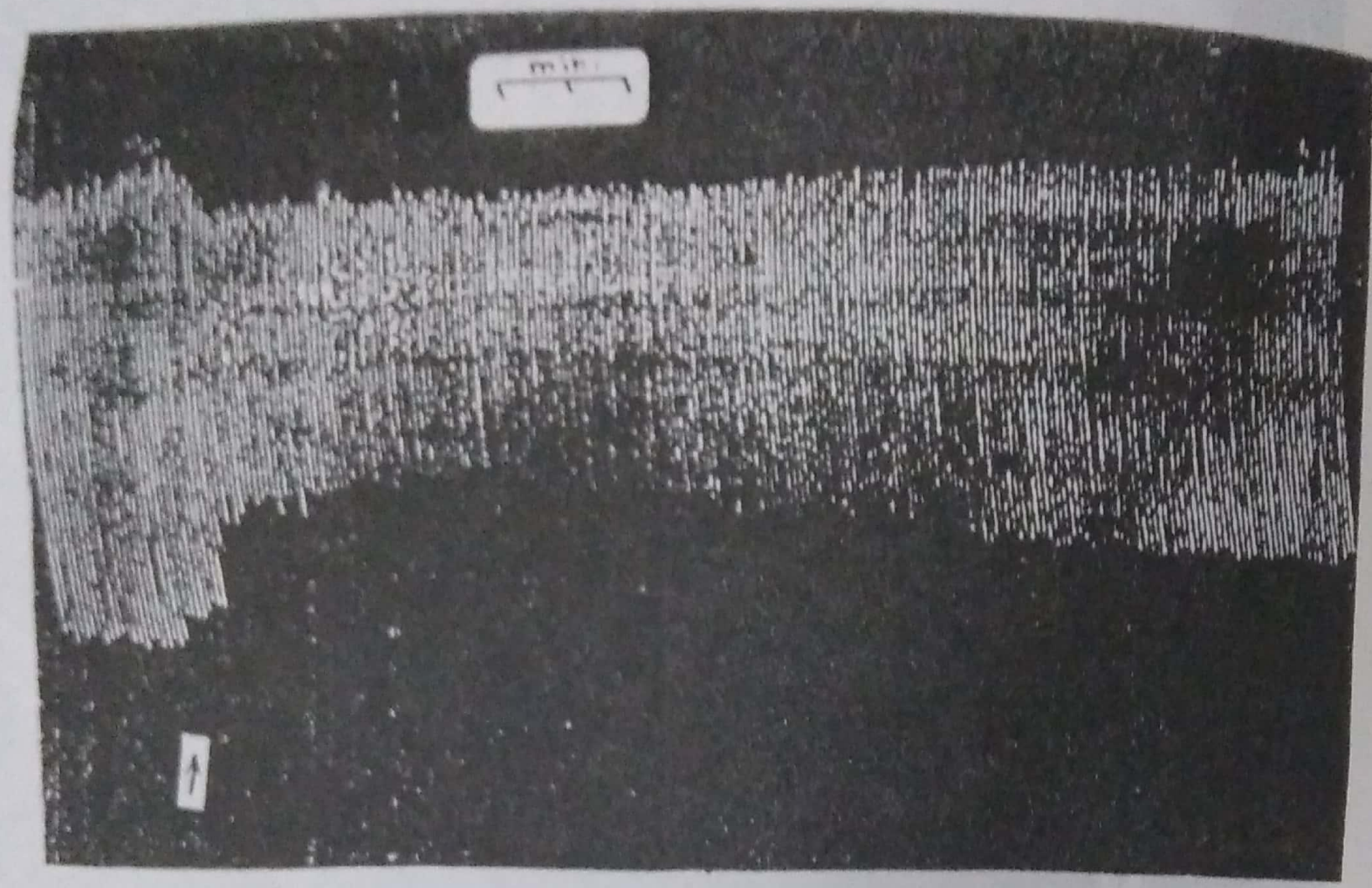

gallamine

$(0.7 \mathrm{mg} / \mathrm{kg})$

Fig. (2): The effect of gallamine $(0.7 \mathrm{mg} / \mathrm{kg}$. i.v) on the indirectly elicited muscle twitches of the upper lip muscles of dogs. The nerve was stimulated by a square pulse wave of 6 volts and of 1 msec.duration repeated every 10 seconds interval.

Time interval: 1 minute.

Note : Partial neuromuscular blockade induced by gallamine. 


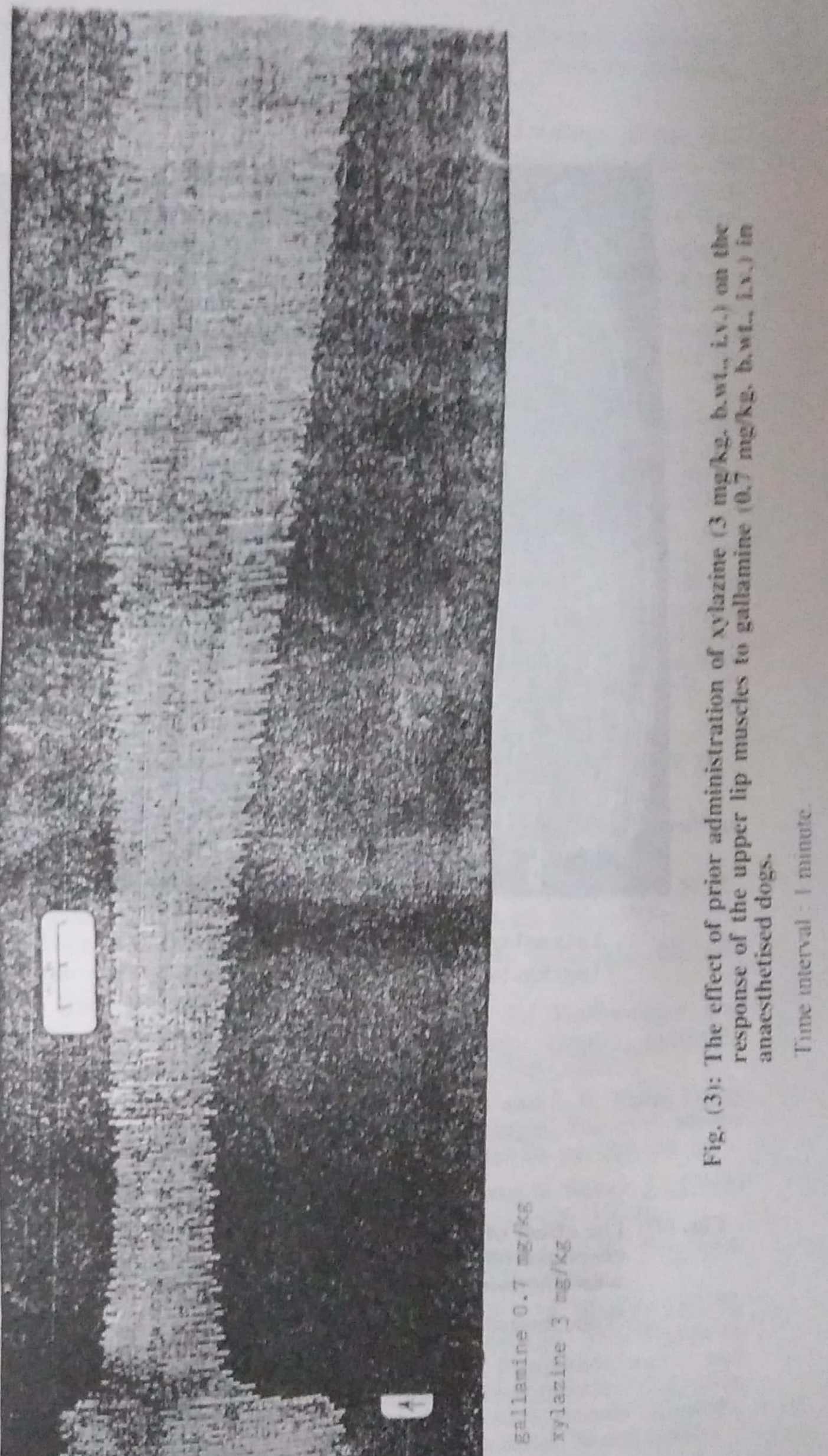




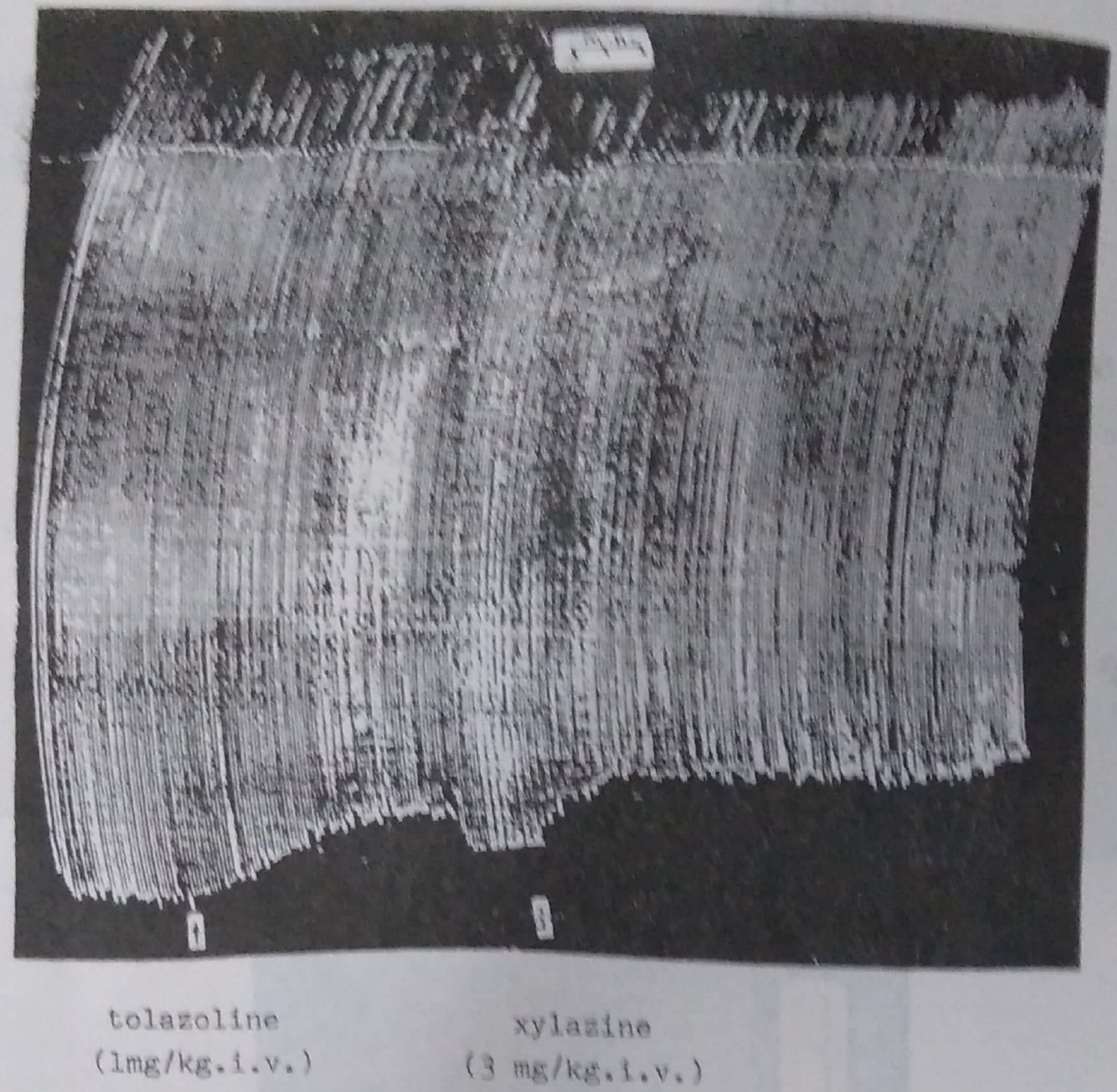

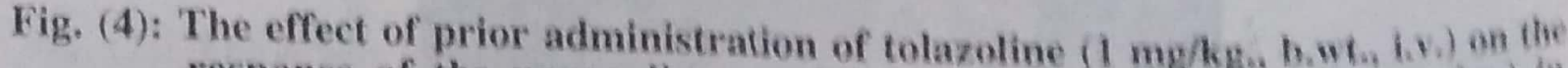

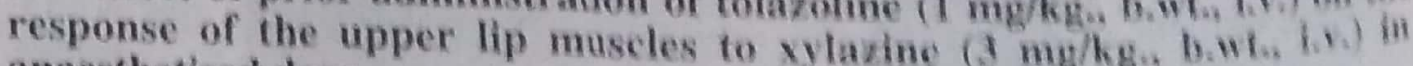
anaesthetised dogs.

Time interval: I minute. 
Xylazine may have a local anaesthetic activity and this property may enhance the previously recorded neuromuscular blockade induced by xylazine (is a point of research). This inhibitory effect of xylazine on the neuromuscular transmission might be attributed to its $\propto 2$-adrenoceptor agonist activity. It was suggested that the neuromuscular effect of xylazine on isolated rat diaphragm and chick biventor muscles was neither depolarizing nor competitive in nature ${ }^{(12)}$. Moreover, previous work reported that the centrally active $\propto$ 2-adrenoceptor agonists cause sedation and decrease in locomotor activity $(\mathbf{1 3}, \mathbf{1 4})$. Furthermore, it has been reported that yohimbine $(\propto 2$-adrenoceptor antagonist) blocks sedation and depression of motor activity induced by xylazine, clonidine and 2 -aminotetralines in rats, mice and dogs ${ }^{\mathbf{( 1 5 - 1 7}}$. It has been found that the injection of tolazoline i.v. enabled camels immobilized with xylazine to stand within 12 mins. compared with one hour or more without tolazoline ${ }^{(5)}$. Moreover, it has been reported that yohimbine reduced the time to stand of the sheep to xylazine from 95 to 2.8 mins $^{(18)}$. The potentiation of the neuro- muscular blockade by local anaesthetics has been confirmed by many workers $(\mathbf{1 9 , 2 0 )}$. Local anaesthetics inhibit the acetylcholine release by a prejunctional effect and cause a membrane stabilization as well as a decrease response to indirect and direct stimulation $^{(21)}$. The local anaesthetics enhance desensitization of acetylcholine receptor and antagonise the action of calmodulin $(22,23)$

In the present study, the prior administration of tolazoline $(\propto)$ and $\propto 2$. adrenoceptors antagonist) significantly reduced the inhibitory effect of xylazine on the neuromuscular transmission. These results show that xylazine significantly augmented and potentiated the neuromuscular blockade induced by the competitive muscle relaxant
gallamine.

The present findings show that xylazine significantly prolonged the duration of anaesthesia of thiopental sodium in dogs. This coordinated with other authors previously ${ }^{(24-26)}$ reported that xylazine prolonged the anaesthetic effect of chloral hydrate as well as the combination of xylazine-ketamine induced surgical anaesthesia in rats for up to 2 hours without regidity.

The prolongation of neuromuscular blockade induced by a combination of xylazine and gallamine might be of clinical importance.

\section{ACKNOWLEDGEMENT}

The authors are grateful to Prof. Dr. A.F. El-Sawi,Pharmacology Department, Faculty of Veterinary Medicine, Alexandria University for his valuable advice during the experimental work.

\section{REFERENCES}

(1) K.W. Clark and L. W. Hall, Vet. Rec., 85, 512 (1969).

(2) S.J. Burns and W.C. MeMullan, VMSAC., 67, 77 (1972).

(3) R.J. Moye, A. Pailet and M.W. Smith, VMSAC., 68, 236 (1973).

(4) W.D. Yates, VMSAC., 68, 483 (1973).

(5) G. Sagner, F. Hoffmeister and S. Kronenberg, Dtsch. Tierarzti. Wochenshr. 75, 566 (1968).

(6) J.S. Spinelli and L.R. Enos, Drugs in Veterinary Practice. The C.V. Mosby Co. U.S.A. chapter 14, pp. 220 (1978).

(7) D.F. Freed and B. Baker, I. of Wild life Diseases, 25 (1), 136 (1989).

(8) N. Jarvis and G.C.W. England, Vet. Rec., 128, 323 (1991).

(9) A.F. El-Sawi, I.M. Shokry and M. Fayez, Proceedings, the Egyptian Society of Pharmacology and Experimental Therapeutics (Egyptian Medical Association Annual Scientific conference, Alexandria, March (1985). 


\section{El-Ashmawy, et al.}

(10) C. Meistelman, J. Loose, P. Saint, M.M. Delleur and G.L. Silva, Br. Anaesth., 58, 996 (1986).

(11) G.W. Snedecor and W.G. Cochran, "Statistical Methods" 6th Ed. The Lowa State Univ. press Ames, Lowa, U.S.A.

(12) M.A. Aziz and R.J. Martin, Zbl. Vet. Med., 25A 181 (1978).

(13) S. Bethelsem and W.A. Pettinger, Life Sci., 21, 596 (1977).

(14) M.R. Goldbery and D. Robertson, Pharmacol. Review, 35, 2, 243 (1983).

(15) Y. Nomura, K. Oki and T. Segawa, Naunyn-Schmiedebergls Arch Pharmacol., 311, 41 (1980).

(16) B. Costall, S.K. Lim and R.J. Naylor, Eur. J. Pharmacol., 73, 175 (1981).

(17) R. G. Hatch, N.H. Booth, J.D. Clark, L.M. Carwford J.V. Ritzman and B. Wallhner, Am. J. Vet. Res., 43, 1009 (1982).

(18) 20-H.A.N. Canabrava, A.C.T. Freire and J.M. Pessoa, Arquivo
Brasileiro de Medicina Veteriniae
Zootecnia, 41 (4) 279 (1989). (19) L.S. Telvinuo and R.L. Katz,
Anaesth., 25,30 (1970). (20) M. Kordas, J. Physiol. 209, 689
(1970).

(21) A.S. Feldman, Muscle Relaxant. 1 st (Ed.) W.B. Saunders Company pp.

(22) R. Anwyl and T. Narhashi, Br. J. Pharmacol., 69, 99 (1980).

(23) M. Volpi, R.I. Shaafi, P.M. Epstein, D. Andrenyak and $B$. Feinsteis, Proc. Natl. Acad. Sci. U.S.A. 78, 795 (1981).

(24) 21-E. Kosicky and A. Martinko, Veterinarstvi, 37 (5) 226 (1987).

(25) 22- W. H. Hsu, J. Pharmacol. Exp. Ther., 218, 188 (1981).

(26) 23-W.H. Hus, S.I. Bellin, H.D. Dellman and C.E. Hanson, JAVMA, 189,102 (1986). Brasileiro de Medicina $\frac{\text { Veteriniae Zootecnia, } 41 \text { (4) } 279}{(1989) \text {. }}$

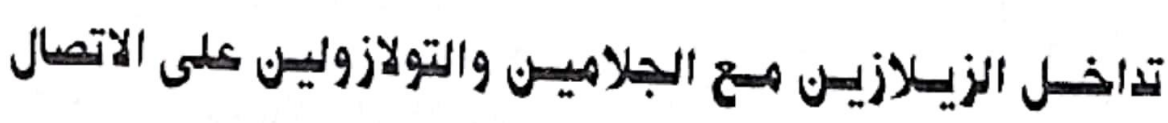

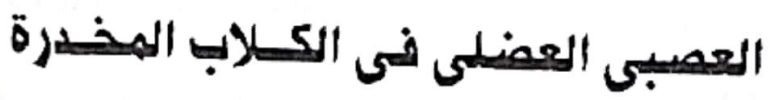

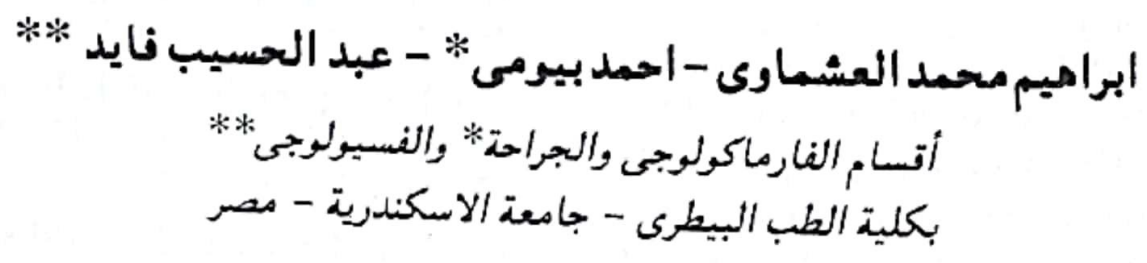

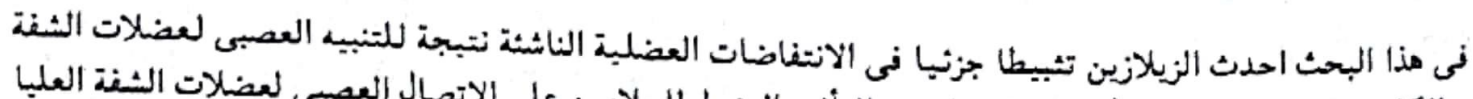

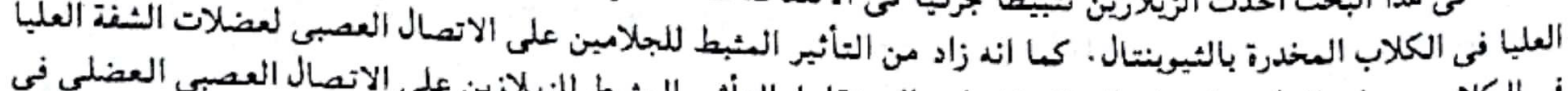

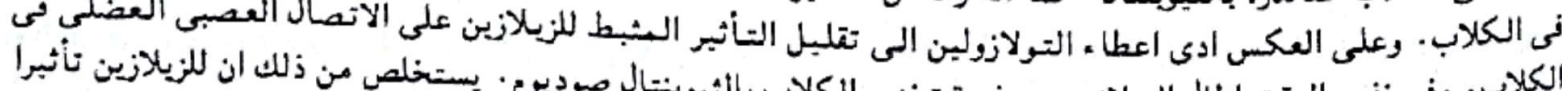

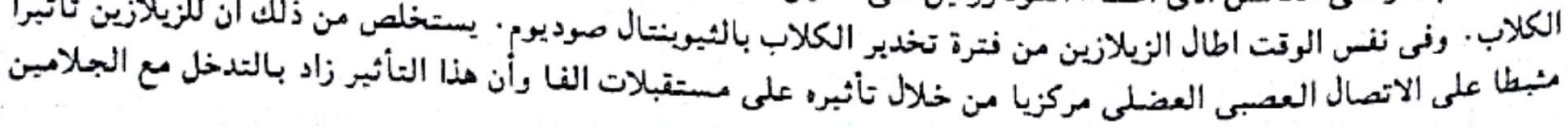
وقل مع اضانة التولازولين. 